\title{
Is point-of-care accurate for indicating thrombolysis in anticoagulated patients on oral anticoagulation treatments?
}

\author{
Teste rápido de RNI tem acurácia para indicar trombólise em pacientes em uso de \\ anticoagulante oral?
}

Tatiana P. Bruch, Danielle C. Mendes, Jeff C. Pedrozo, Livia Figueiredo, Edison M. Nóvak, Viviane F. Zétola, Marcos C. Lange

\begin{abstract}
The use of oral anticoagulation treatment (OAT) in patients with an international normalized ratio (INR) higher than 1.7 is a contraindication to thrombolysis in acute ischemic stroke. The aim of the present study is to compare the use of point-of-care (POC) coagulometers to the standard coagulation analysis (SCA) procedure of the INR as a decision-making test for use with patients taking OAT. Method: Eighty patients on chronic OAT underwent a POC and an SCA during a regular outpatient evaluation. Results: When comparing the abilities of the POC test and the SCA test to identify adequate levels for thrombolysis ( $\leq 1.7)$, the POC had a sensitivity of 96.6\% (95\% Cl 88.4-99.1) and a specificity of $60.0 \%(95 \% \mathrm{Cl} 38.6-78)$. POC overestimated INR levels by 0.51 points compared to the SCA test. Conclusion: POC has a high sensitivity compared to the SCA test for the identification of patients within the cut-off point for thrombolysis.
\end{abstract}

Keywords: ischemic stroke, thrombolytic therapy, warfarin, contraindications, anticoagulation.

RESUMO

Valores acima de 1.7 no RNI de pacientes em uso de terapia anticoagulante (ACO) é uma contraindicação para a trombólise no AVC isquêmico. O Objetivo do presente estudo é comparar o teste capilar rápido (TCR) com o exame tradicional de RNI como método de decisão para indicação de terapia trombolítica em pacientes em uso de ACO. Método: Oitenta pacientes em uso crônico de ACO foram submetidos ao TCR e ao exame tradicional durante consulta ambulatorial. Resultados: Ao serem comparados os resultados do TCR com o exame tradicional com o ponto de corte de 1,7 de RNI, o teste rápido teve sensibilidade de 96,6\% (IC95\% 88,4-99,1) e especificidade de 60,0\% (IC95\% 38,6-78). O TCR superestimou os niveis de RNI em 0,51 pontos comparado ao exame tradicional. Conclusão: O TCR apresentou elevada sensibilidade, comparado ao exame tradicional para a identificação de pacientes em uso de ACO com indicação de trombólise.

Palavras-chave: acidente vascular cerebral, terapia trombolítica, testes de coagulação sanguínea, varfarina, antagonistas da vitamina K, anticoagulação oral.

Intravenous thrombolytic therapy has been shown to be a highly effective therapy for patients with acute ischemic stroke (IS) ${ }^{1}$. The current use of vitamin $\mathrm{K}$ antagonists as oral anticoagulation treatment (OAT) with an international normalized ratio (INR) higher than 1.7 is an absolute contraindication to this treatment ${ }^{1,2}$. Moreover, patients taking OAT with acute IS symptoms must have their INR results before infusion of the thrombolytic drug. This situation delays the symptom-to-needle time to treat, reducing the opportunity for a better functional outcome. The aim of this study was to compare the accuracy of point-of-care (POC) coagulometers to standard coagulation analysis (SCA) procedure INR in patients on chronic OAT.

\section{METHOD}

The authors evaluated patients followed in the outpatient clinic between August and October 2012. The inclusion criteria were as follows: 1) regular OAT longer than three months; 2) at least one previous therapeutic INR in another outpatient evaluation; and 3) older than 18 years 
of age. The local hospital ethics committee authorized this study.

All patients who visited the outpatient clinic and fulfilled the inclusion criteria received an explanation of the study. Those who agreed underwent POC INR analysis. A drop of blood from the index finger was collected directly onto a test strip inserted in a CoaguChek XL system (Roche Diagnostics, Germany), and the INR result was read after a few seconds. Immediately after this procedure, a $3.5 \mathrm{~mL}$ blood sample was collected aseptically in a vacuum tube containing sodium citrate through a peripheral venous puncture in the same arm and sent for the SCA procedure in a central laboratory (SA 1500, Fymex, Japan). This process required approximately 40 minutes to complete.

The statistical analyses were performed by using statistical software (Epi Info 6.04 software) and statistical significance was set at $\mathrm{p}<0.05$. The Chi-squared test was performed to analyze the sensitivity, specificity, positive predictive value (PPV), negative predictive value (NPV) and accuracy of the diagnosis by POC INR compared to the gold-standard (SCA INR). True-positive cases were defined as those in which the INR results, by POC and SCA, were correctly determined considering the threshold value (INR $\leq 1.7$ ). False-positive cases were defined as those in which the INR results by POC were equal or less than 1.7 and by SCA were higher than 1.7. The paired-sample $t$ test was performed to correlate the two variables (INR by POC and INR by SCA) with $\mathrm{P}<0.05$ indicating significance. Linear regression was performed to determine if gender or age interfered with the accuracy of the capillary test. Receiver operating characteristic (ROC) curve was generated to help establish the area under the curve (AUC) for the threshold value for the administration of intravenous thrombolysis (INR $\leq 1.7$ ), the null hypothesis tested was that the AUC was 0.5 ; the alternative was that this area was greater than 0.5 .

\section{RESULTS}

During the study period, 80 patients receiving OAT were evaluated. From this group, $48(60 \%)$ were female, and the mean age was $61.1 \pm 13.2$ years. The primary indication for OAT was cardioembolic stroke in 34 patients (42.5\%), metallic prosthetic valve in 15 patients $(18.75 \%)$, cerebral venous thrombosis in 13 patients (16.25\%), other arrhythmia in seven patients $(8.75 \%)$, Chagas disease in three patients (3.75\%), thrombophilia in three patients $(3.75 \%)$ and other diagnoses in five patients (6.25\%). Fifty-nine (73.75\%) patients were taking warfarin, and the other 21 patients $(26.25 \%)$ were taking fenprocoumon.

Only 46 patients (56.2\%) were within therapeutic INR target values based upon each disease indication. Of those with an INR outside the target ( $\mathrm{n}=34), 25$ (73.53\%) patients were undertreated and nine $(26.47 \%)$ were overtreated.

When comparing the abilities of the POC INR test and the SCA test to report adequate levels for the administration of intravenous thrombolysis (INR $\leq 1.7$ ), the POC had a sensitivity of $96.6 \%$ (95\%CI 88.4-99.1), a specificity of $60.0 \%$ (95\%CI 38.6-78.1), a PPV of 85.7\% (95\%CI 75.9-92.1) and a NPV of $81.2 \%$ (95\%CI 53.7-95.1) with an accuracy of $81.3 \%$ (95\%CI 75.2-87.3) $(\mathrm{p}<0.001)$. The AUC observed for the threshold value for the administration of intravenous thrombolysis (INR $\leq 1.7)$ was 0.54 .

The intraclass correlation coefficient between the tests was 0.86 , and the POC INR test overestimated the anticoagulation blood level by 0.51 .

Linear regression was performed to determine if gender or age interfered with the accuracy of the CoaguChek XL ${ }^{\circledR}$ system; neither interfered $(\mathrm{p}>0.08)$.

\section{DISCUSSION}

In patients on chronic OAT with vitamin $\mathrm{K}$ antagonists, the present study demonstrated that the POC INR test has a high sensitivity and a moderate specificity compared to the SCA test for identifying patients with contra-indications to thrombolytic therapy. An INR cut-off value equal or less than 1.7 in the POC could be used for initiating thrombolytic therapy in patients taking OAT.

Oral anticoagulants have a wide variation in the relationship between dose and response to therapy based upon individual metabolism ${ }^{3}$. Therefore, it is necessary to periodically monitor the prothrombin time of patients using these medications ${ }^{3}$. The current study identified an excellent correlation between the POC and the SCA INR, similar to that shown in previous studies. This finding demonstrates that the POC device is accurate, reliable and comparable to the SCA INR for use in patients with long-term use of oral anticoagulants ${ }^{4,5,8,10}$.

POC could be useful in several situations, as patients without access to a medical laboratory could achieve better control with $\mathrm{OAT}^{6}$; and in patients with acute IS who are within the therapeutic window for thrombolysis, evaluating INR using POC could be performed in the pre-hospital emergency medical service or in the hospital emergency room, reducing the time to treatment.

The speed and ease of the POC could improve the chance of treatment in this selected population ${ }^{2}$. The chances of complication, such as infection or hematoma at the puncture site, are practically null ${ }^{2}$. However, this method should not replace SCA INR analysis because it is the "gold standard" procedure. Additionally, in the current study, the specificity of the POC was only moderate (60\%). Patients with an INR higher than 1.7 based upon their POC must wait for 
laboratory results to confirm the results. A previous study demonstrated that higher INR showed worse correlation between the laboratory and capillary tests ${ }^{7}$.

One of the limitations of the present study was the sample size. Although it was not very large, the size is similar to previous studies published in this setting. Due to increasing numbers of users of OAT, studies can be used to guide future trials that accurately reflect the true target population? Additionally, it is noteworthy that the patients were observed in an outpatient clinic, and they were not studied during an acute IS. In a previous study, POC INR was precise for emergency management of thrombolysis in patients with acute IS and reduced the interval to INR results. The time gain using the POC compared to INR was 28 minutes $^{8}$. This delay could compromised the effectiveness of thrombolysis in acute stroke care.

In conclusion, the POC INR test was useful for screening patients taking OAT. In a selected population, if the INR is equal or less than 1.7 in the POC test, then the patient could be submitted to thrombolysis; otherwise, the results from the central laboratory must be reviewed prior to administering the treatment. Randomized controlled trials should be performed to determine whether these advantages are cost-effective.

\section{References}

1. Lansberg MG, Bluhmki E, Thijs VN. Efficacy and safety of tissue plasminogen activator 3 to 4.5 hours after acute ischemic stroke: a metaanalysis. Stroke 2009;40:2438-2441.

2. Hacke W, Kaste M, Bluhmki E, et al. Thrombolysis whith alteplase 3 to 4.5 hours after acute ischemic stroke. N Engl J Med 2008;359:1317-1329.

3. Holbrook AM, Pereira JA, Labiris R, et al. Systematic overview of warfarin and its drug and food interactions. Arch Intern Med. 2005;165:1095-1106.

4. Douketis JD, Lane A, Milne J, Ginsberg JS. Accuracy of a Portable International Normalization Ratio Monitor in outpatients receiving long-term oral anticoagulant therapy: comparison with a laboratory reference standard using clinically relevant criteria for agreement. Thrombosis Res 1998;92:11-17.

5. Cosmi B, Palareti G, Moia M, et al. Accuracy of a portable prothrombin time monitor (coagucheck) in patients on chronic oral anticoagulant therapy: a prospective multicenter study. Thrombosis Res 2000;100:279-286.
6. Bereznicki LR, Jackson SL, Peterson GM, Jeffrey EC, Marsden KA, Jupe DM. Accuracy and clinical utility of the CoaguChek XS portable international normalised ratio monitor in a pilot study of warfarin home-monitoring. J Clin Pathol 2007;60:311-314.

7. Leiria TL, Pellanda LC, Magalhães E, Lima GG. Comparative study of a portable system for prothrombin monitoring using capillary blood against venous blood measurements in patients using oral anticoagulants: correlation and concordance. Arq Bras Cardiol 2007;89:1-5.

8. Rizos $T$, Herweh $C$, Jenetzky $E$, et al. Point-of-care internationa normalized ratio testing acelerates thrombolysis in patients with acute ischemic stroke using oral anticoagulants. Stroke 2009;40:3547-3551.

9. Drescher MJ, Spence A, Rckwell D, Staff I, Smally AJ. Poin-of -care testing for coagulations studies in a stroke protocol: a time saving innovation. Am J Emerg Med 2011;29:82-85.

10. Jonsson M, Hillarp A, Svensson P. Comparison between CoaguChek S- and Owren-type prothrombin time assay for monitoring anticoagulant therapy. Thrombosis Res 2004;114:83-89. 